\title{
O cupação do solo, fragmentação da paisagem e qualidade da água em uma pequena bacia hidrográfica
}

\author{
Henrique M. L. Chaves ${ }^{1} \&$ Loyane B. dos Santos ${ }^{1}$
}

\begin{abstract}
RESUMO
A intensidade de uso e ocupação do solo e a fragmentação da paisagem, estimadas através de técnicas de processamento de imagens de satélite, foram relacionadas a parâmetros químicos e físicos de qualidade de água, medidos em 3 pontos de captação do córrego Ponte de Terra, localizado no Distrito Federal. Os parâmetros analisados, coletados mensalmente na bacia $(A=9,8$ km²), foram: a cor, a turbidez, a condutividade elétrica, a concentração de amônia, a demanda química de oxigênio (DQ 0 ) e 0 índice de qualidade da água (IQ A). Estudou-se, também, a estacionariedade das séries históricas dos parâmetros entre os anos de 1992 e 2005, quando a bacia sofreu um processo significativo de ocupação do solo. Indicadores de intensidade de ocupação do solo $\left(L U I_{m}\right)$ e a fragmentação da paisagem $\left(F_{p}\right)$ foram desenvolvidos e calculados para a bacia, usando-se as proporções de áreas de diferentes graus de modificação e a entropia espectral da imagem, respectivamente. A pesar do uso/ ocupação do solo e da fragmentação da paisagem terem aumentado significativamente no período estudado, apenas a DQ 0 (média das 3 captações) aumentou de forma significativa. Como a zona ripária se manteve relativamente íntegra no período estudado, é possível que ela tenha amenizado eventuais impactos à qualidade da água na bacia.
\end{abstract}

Palavras-chave: dinâmica do uso do solo, sensoriamento remoto, impacto, hidrologia

\section{Land use, landscape fragmentation, and water quality in a small watershed}

\begin{abstract}
Land-use intensity and landscape fragmentation, estimated by digital processing of remotely-sensed images, were related to chemical and physical parameters of water, measured in 3 points of the Ponte de Terra stream ( $9.8 \mathrm{~km}^{2}$ of basin area), located in Brasilia, Brazil. The water quality parameters studied were the colour, turbidity, conductivity, concentration of ammonia, chemical oxygen demand (COD), and the water quality index (IQA). The stationarity of the time series of the parameters was also studied in the period between 1992 and 2005, when the basin experienced a significant occupation process. Land-use intensity $\left(\mathrm{LUI}_{\mathrm{m}}\right)$ and landscape fragmentation $\left(\mathrm{F}_{\mathrm{p}}\right)$ indicators were developed and calculated for the basin using the proportions of different use intensity classes, and the spectral entropy of the satellite images, respectively. Despite the fact that the landuse and landscape fragmentation increased significantly in the studied period, only the COD parameter (mean of the 3 points) increased significantly. As the riparian zone remained relatively undisturbed in the period, it is possible that it buffered eventual impacts on the water quality of basin.
\end{abstract}

Key words: land use dynamics, remote sensing, impact, hydrology 


\section{INTRODUÇãO}

Cursos d'água servem como integradores das características da paisagem terrestre e como recipientes dos poluentes da terra e da atmosfera. A qualidade de sua água, por sua vez, resulta de fatores geomórficos, climáticos, hidrológicos e biológicos, sendo o tipo de uso e o manejo do solo determinantes para a qualidade da água em bacias hidrográficas (Hunsaker et al., 1998).

Enquanto grandes rios são bons indicadores dos impactos cumulativos, rios menores apresentam maiores variabilidades na qualidade da água, dependendo da estação do ano e do grau de distúrbio da bacia (Cada \& Hunsaker, 1990).

Apesar da relação entre a mudança do uso do solo e a qualidade da água ser reconhecida na literatura, os vários fatores que intervêm no processo e a sua característica dinâmica tornam sua determinação quantitativa difícil e elusiva; em função disso, a maior parte dos estudos na área tem sido empírica, relacionando o tipo de uso, cobertura e manejo do solo com a qualidade da água (Johnson et al., 1997; Herlihy et al., 1998; Hunsaker et al., 1998; May et al., 1999; Ometo et al., 2000; Rhodes et al, 2001; Roy et al., 2003;). A maioria desses estudos mostra uma piora na qualidade de água com o aumento do uso e ocupação do solo.

Dentre as bacias mais impactadas no tocante à qualidade da água estão aquelas que sofrem processo de ocupação acelerada. Apesar da impermeabilização do solo em áreas urbanas não gerar, por si só, poluição, ela é o maior contribuinte das mudanças na hidrologia da bacia, responsáveis por grande parte das mudanças físicas que afetam os rios urbanos (May et al., 1999); neste sentido, o valor de $10 \%$ de impermeabilização do solo foi identificado por alguns autores como o limite no qual começa a degradação dos ecossistemas hídricos (Schueler, 1994; Booth \& Jackson, 1997; May et al., 1999).

Contrariamente, bacias com maiores proporções de cobertura vegetal e áreas ripárias protegidas apresentam melhor qualidade de água (Hunsaker et al., 1998; Rhodes et al., 2001). Riemann et al., (2004), estudando as respostas na qualidade da água de 43 pequenos rios dos EUA, cujas bacias sofriam um processo de urbanização, concluíram que a concentração de nitrogênio total, cloretos e pesticidas no escoamento de base, aumentavam com o processo de urbanização da bacia. As variáveis de paisagem estudadas foram as proporções de áreas florestadas e de áreas urbanizadas e o grau de fragmentação das florestas. Segundo esses autores, uma equação de regressão múltipla que usa o percentual de cobertura florestal, sua fragmentação e o percentual de áreas urbanas na bacia, explicou $83 \%$ da variação na concentração de nitrogênio total no escoamento de base da primavera, indicando que a distribuição espacial das florestas remanescentes, além de sua área de recobrimento, é também significativa para a qualidade da água.

Rhodes et al. (2001), estudando o efeito da retirada de água de boa qualidade de zonas de cabeceira de pequenas bacias, concluíram que o uso consuntivo de água dos rios tende a aumentar as concentrações de nitratos e sulfatos a jusante, piorando a qualidade da água.
Não apenas a proporção mas também a posição das áreas florestadas na bacia influenciam a qualidade da água. Johnson et al. (1997) concluíram que a concentração de fósforo total e de sólidos suspensos totais na água foi mais negativamente correlacionada com o percentual de floresta remanescente na zona ripária que aquele em outras áreas na bacia; entretanto, apesar da importância das zonas ripárias na proteção dos cursos d'água contra impactos de aportes de sedimentos, nutrientes e poluentes ser reconhecida na literatura, é difícil separar a proteção oferecida por essas daquela proporcionada por florestas localizadas em áreas de interflúvio (Allan, 2004; Houser et al., 2006).

O processo de ocupação do solo no Distrito Federal tem sido acelerado nos últimos 50 anos, com a construção e a consolidação de Brasília. O cerrado original que recobria a região vem dando lugar a áreas agrícolas e urbanas. Em 1954, o DF, que tinha uma cobertura vegetal original de 329.000 ha apresentava, em 1998, uma cobertura nativa de apenas 124.000 ha, ou seja, uma redução relativa de 62\% (UNESCO, 2000).

Apesar de boa parte dos mananciais do Distrito Federal ter suas bacias de drenagem protegidas por lei - através de áreas de proteção de mananciais (APMs) - alguns deles sofrem uma ocupação acelerada, ameaçando tanto a quantidade como a qualidade de água; dentre esses está o manancial do córrego Ponte de Terra, operado pela CAESB. Abastecendo a cidade do Gama (100.000 hab.), este manancial, que até 1985 era relativamente bem preservado, com grande parte de sua bacia sob vegetação natural, vem sofrendo um processo de desmatamento e ocupação humana com a criação de condomínios, comércios, estradas e ruas. Das 3 captações construídas pela Companhia de Saneamento Ambiental do Distrito Federal (CAESB) no manancial, uma delas (a captação Ponte de Terra 1) já foi desativada.

Considerando o exposto, o objetivo do presente trabalho foi estudar a relação entre a ocupação no solo e a fragmentação da paisagem da bacia do córrego Ponte de Terra e a qualidade da água do manancial, durante o período compreendido entre 1986 e 2005, através da análise das séries temporais dos parâmetros de qualidade da água e do processamento digital (multi-temporal) de imagens de satélite da área.

\section{MATERIAL E MÉTODOS}

\section{Descrição da área de estudo}

A bacia (APM) do córrego Ponte de Terra, com área total de $9,8 \mathrm{~km}^{2}$, está localizada no sudoeste do Distrito Federal e se situa entre 3 grandes núcleos urbanos: as cidades de Brasília (a norte), de Taguatinga e Ceilândia (a norte), e do Gama (a sudoeste) (Figura 1). O córrego Ponte de Terra é afluente do ribeirão Ponte Alta que desagua no Corumbá, fazendo parte da bacia hidrográfica do rio Paraná.

A bacia apresenta relevo plano a suave ondulado, solos profundos e bem drenados (dominantemente Latossolos). A Companhia de Saneamento Ambiental do Distrito FederalCAESB possui 3 captações de abastecimento humano no córrego Ponte de Terra, mostradas na Figura 2. 


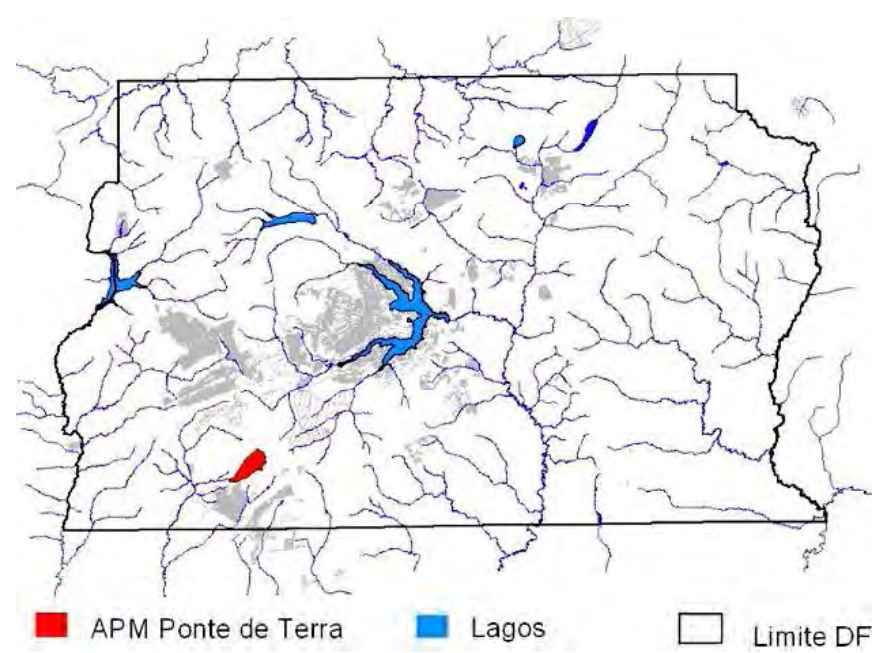

Figura 1. Localização da bacia (APM) do Ponte de Terra, no Distrito Federal

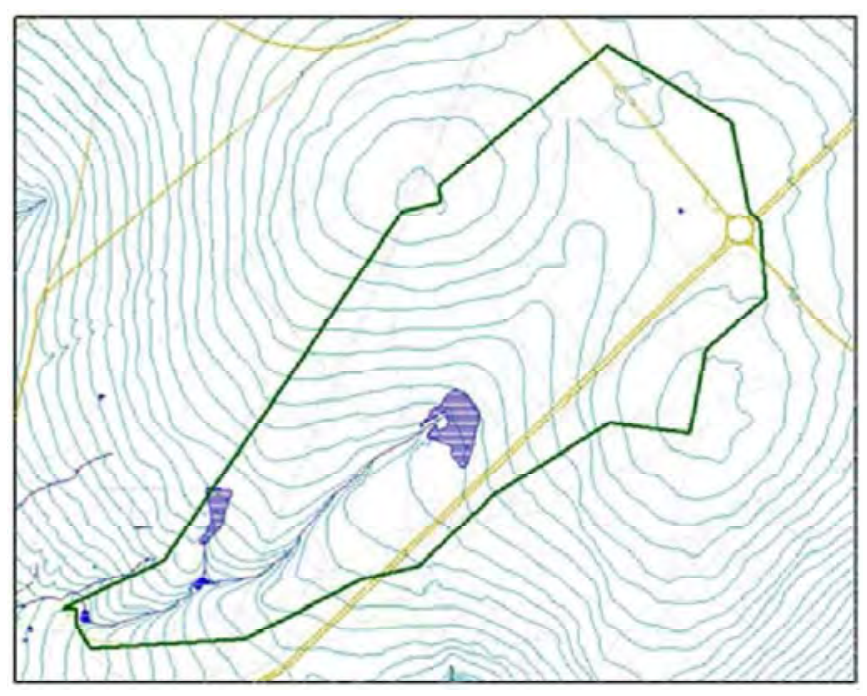

Figura 2. Bacia (APM) do córrego Ponte de Terra (linha grossa), com suas 3 captações (1, 2 e 3, da direita para a esquerda, respectivamente)

\section{Análise multi-temporal do uso e ocupação do solo da bacia}

Evolução do grau do uso e ocupação do solo: Para se avaliar a evolução do uso e da ocupação no solo da bacia do córrego Ponte de Terra, imagens de satélite LANDSAT TM e ETM+ (bandas 3, 4 e 5) obtidas nos meses de inverno dos anos 1986, 1993, 1998, 2001 e 2003 foram selecionadas. Depois de feitas as correções geométricas e atmosféricas, realizou-se uma classificação não supervisionada, pelo método de K-médias (Mather, 1999), com auxílio do software ENVI ${ }^{\circledR}$ Versão 4.5 .

A escolha da classificação não-supervisionada se deu em função da inexistência de dados sobre a verdade do terreno no período estudado, exceto aqueles relativos a 2006; tomando-se este ano como base se definiram, através de segmentação, 5 classes de mesma amplitude espectral, correspondendo ao grau de modificação em relação ao padrão natural (cerrado) atribuindo-se, às classes, valores de 0 a 4 . O grau de modificação, por sua vez, está correlacionado com a intensidade de uso e ocupação do solo.
As classes de uso do solo usadas e suas características foram:

Classe 0 (não modificada): Condição natural ou quase natural (cerrado nativo ou mata galeria), caracterizando baixíssimo grau de uso e ocupação do solo;

Classe 1 (pequena modificação): Vegetação natural com pequena modificação, tais como a retirada de lenha, como pastagens nativas, caracterizando baixo grau de uso e ocupação do solo;

Classe 2 (modificação média): Áreas com grau médio de modificação (transição), tais como pastagens plantadas e parques, caracterizando médio grau de ocupação do solo;

Classe 3 (alta modificação): Áreas de média a forte modificação da condição inicial, tais como áreas desmatadas, quintais, pomares e ruas de terra, caracterizando alto grau de uso e ocupação do solo;

Classe 4 (modificação muito alta): Áreas com grau muito alto de modificação da condição original, tais como edificações, solo exposto, áreas degradadas e ruas pavimentadas, caracterizando uso e ocupação muito alta do solo.

Depois de classificadas as imagens, de acordo com as classes da Tabela 1, mapas e tabelas de intensidade de ocupação/modificação da cobertura do solo foram gerados para a bacia, em cada um dos 5 anos estudados.

Tabela 1. Classes de fragmentação da paisagem, baseadas na entropia das imagens

\begin{tabular}{cccc}
\hline $\begin{array}{c}\text { Classe de } \\
\text { entropia }\end{array}$ & $\begin{array}{c}\text { Intervalo de DN da imagem } \\
\text { após o filtro de entropia }\end{array}$ & $\begin{array}{c}\text { Classe de } \\
\text { fragmentação }\end{array}$ & Peso da classe \\
Baixa & $0-85$ & Baixa & 1 \\
Média & $86-170$ & Média & 2 \\
Alta & $171-255$ & Alta & 3 \\
\hline
\end{tabular}

Buscou-se, na literatura, um indicador capaz de integrar as diferentes classes de grau de uso e suas respectivas frequências em um único número, como o Índice de Uso da Terra (LUI), descrito por Ometo et al. (2000). Esses autores definiram o LUI como o produto do tipo de uso do solo (urbano, agrícola, florestal etc.), suas frequências relativas e ainda propuseram diferentes pesos para as classes variando de 0 (áreas não modificadas) até 10 (áreas urbanizadas).

Em função das características específicas da bacia estudada, desenvolveu-se um índice modificado, cujos pesos variaram de 1 a 5 para as classes de grau de uso de 0 a 4 (Tabela 1), respectivamente. Este indicador, aqui denominado Índice de Uso da Terra Modificado $\left(\mathrm{LUI}_{\mathrm{m}}\right)$, é dado pela equação:

$$
\mathrm{LUI}_{\mathrm{m}}=\sum_{\mathrm{i}-1}^{5} \mathrm{~F}_{\mathrm{i}} \mathrm{P}_{\mathrm{i}}
$$

em que: $\mathrm{F}_{\mathrm{i}}$ é a proporção de área da classe i e $\mathrm{P}_{\mathrm{i}}$ é o peso (15) da classe $i$, conforme descrito acima. $O$ valor de $\mathrm{LUI}_{\mathrm{m}}$ foi assim calculado para a bacia, em cada ano, e posteriormente correlacionado com os parâmetros de qualidade da água.

Grau de fragmentação da paisagem: Além do grau de uso e ocupação do solo, estimou-se também o grau de fragmentação da paisagem na bacia, durante o período estudado (1986- 
2003); para tanto, as imagens de satélite dos anos de 1986, 1998 e 2003, depois de terem sido classificadas automaticamente no ENVI® pelo método não-supervisionado de K-médias (Mather, 1999), passaram pelo filtro de entropia do mesmo software, usando-se uma janela de 5 x 5 pixels.

De acordo com Shannon (1948), a medida de entropia está relacionada à heterogeneidade da informação; neste caso, as classes de intensidade de uso (0-4) dos pixels da imagem classificada. Ricotta et al. (2006) concluíram que a entropia $(\mathrm{H})$ serve como medida da fragmentação da paisagem quando há incerteza no cálculo da abundância relativa dos fragmentos. Matematicamente, a entropia $(\mathrm{H})$ é dada pela seguinte equação:

$$
\mathrm{H}=-\sum_{\mathrm{i}=1}^{\mathrm{N}} \mathrm{p}_{\mathrm{i}} \ln \mathrm{p}_{\mathrm{i}}
$$

em que:

$\mathrm{p}_{\mathrm{i}}$ é a frequência de ocorrência de uma classe de uso (0 a 1) e $\mathrm{N}$ é o número de classes. O sinal negativo na Eq. 2 é para compensar o valor negativo de $\ln \left(\mathrm{p}_{\mathrm{i}}\right)$, uma vez que $\mathrm{p}_{\mathrm{i}}<1$.

Assim, quanto maior o número de classes diferentes de grau de utilização do solo em uma janela 5 x 5 da imagem, maior também será a entropia do seu pixel central, e vice-versa (Ricotta et al., 2006).

Depois de gerados os mapas de entropia das imagens classificadas, definiram-se 3 classes para cada imagem, em função do nível de cinza (DN) da imagem resultante do filtro de entropia (e, portanto, em função da sua fragmentação), as quais são apresentadas na Tabela 1; desta forma, os pixels da imagem de entropia com valores de DN menores que 85 foram classificados como de baixa fragmentação, 85 < DN < 170 como de média fragmentação e DN > 170 como áreas de alta fragmentação, respectivamente.

Da mesma forma que o grau de uso e ocupação do solo, desenvolveu-se e se aplicou um indicador integrado para a fragmentação da paisagem $\left(\mathrm{F}_{\mathrm{p}}\right)$, dado pela seguinte equação:

$$
\mathrm{F}_{\mathrm{p}}=\sum_{\mathrm{i}=1}^{3} \mathrm{~F}_{\mathrm{i}} \mathrm{P}_{\mathrm{i}}
$$

em que:

$\mathrm{F}_{\mathrm{i}}$ é a proporção de área da classe $\mathrm{i}$ e $\mathrm{P}_{\mathrm{i}}$ é o peso da classe $\mathrm{i}$. No caso do $\mathrm{F}_{\mathrm{p}}$, os pesos foram 1, 2 e 3, para as classes baixa, média e alta de fragmentação (Tabela 1), respectivamente.

Correlação entre o grau de uso e ocupação do solo e a fragmentação: A correlação entre o grau de uso e ocupação do solo e a fragmentação na bacia, durante o período entre 1986 e 2003, foi estimada através de análise visual (gráfico scatter-plot).

\section{Parâmetros de qualidade da água}

Os parâmetros de qualidade da água analisados no presente trabalho foram: a cor (UC), a turbidez (UT), a condutividade elétrica $\left(\mathrm{mS} \mathrm{cm}^{-1}\right)$, a demanda química de oxigênio $(\mathrm{mg}$ $\left.\mathrm{L}^{-1}\right)$, a concentração de amônio $\left(\mathrm{mg} \mathrm{L}^{-1}\right)$ e o Índice de Qualidade da Água-IQA (adimensional). Amostras de água foram coletadas e analisadas pela CAESB, de acordo com os proce- dimentos padrão (NSF, 1995), em uma frequência mensal a bimestral. O período analisado foi de 1992 a 2005.

Estacionariedade das séries temporais dos parâmetros de qualidade da água: Os dados de qualidade da água foram divididos por ponto de captação e por estação do ano (seca e úmida); esta divisão de estações é frequentemente usada na literatura, pois pode haver uma variação significativa entre os dois períodos, em função do maior transporte de nutrientes e sedimentos durante a estação chuvosa (Johnson et al., 1997; Clinton \& Vose, 2006).

Para identificar o eventual impacto do uso e ocupação do solo da bacia sobre a qualidade da água no período estudado, verificou-se o grau de estacionariedade das séries temporais dos parâmetros de qualidade da água em cada uma das captações, bem como a média das 3 captações, através de análises gráficas e estatísticas de eventuais tendências e/ou ressaltos. No caso da existência de tendência (crescente ou decrescente) das séries históricas, sua significância foi determinada através do teste de $\mathrm{t}$, com base em um modelo linear. De acordo com Salas (1992), uma série apresenta tendência significativa de crescimento (ou decrescimento) linear, se:

$$
\mathrm{t}_{\mathrm{c}}=\left|r \sqrt{\mathrm{N}-2} / \sqrt{1-r^{2}}\right|>\mathrm{t}_{1-\alpha / 2, v}
$$

em que:

r é o coeficiente de correlação entre o parâmetro e o tempo, $\mathrm{N}$ é o número de anos e $\mathrm{t}_{1-\mathrm{a} / 2, \mathrm{n}}$ é o valor tabelado da distribuição de Student para um grau de liberdade $n=$ N-2. A estatística para a determinação de ressaltos na série temporal é semelhante, sendo que a série temporal é sub-dividida em duas, com duas médias e dois desvios-padrão (Salas, 1992).

Correlação entre os parâmetros de qualidade da água e o grau de ocupação do solo: Os métodos usados para a estimativa da correlação entre o grau de uso e ocupação do solo da bacia e a qualidade da água, foram gráficos (scatter plots), linhas de tendência e coeficiente de determinação $\left(\mathrm{R}^{2}\right)$ entre as variáveis estudadas. Da mesma forma que as séries temporais, os dados de qualidade de água foram separados por estações do ano (seca e úmida), e usados os valores médios dos parâmetros de qualidade das 3 captações.

\section{RESULTADOS E DISCUSSÃO}

\section{Evolução do uso e ocupação do solo na bacia}

A Figura 3 mostra o grau de uso e ocupação do solo nos anos de 1986 e 2003; nela, pode-se observar que, no período estudado, houve um aumento significativo das áreas de alto grau de modificação (classes 3 e 4), em detrimento das classes de baixa modificação, ambos em relação à condição original (cerrado). Na mesma figura, se nota que a zona ripária, ao longo do córrego Ponte de Terra, sofreu pouca modificação durante o período estudado, conforme indicam as manchas remanescentes de mata (escuras) ao longo do curso d'água.

A Figura 4, a seguir, mostra graficamente a evolução da ocupação do solo da bacia do córrego Ponte de Terra no 


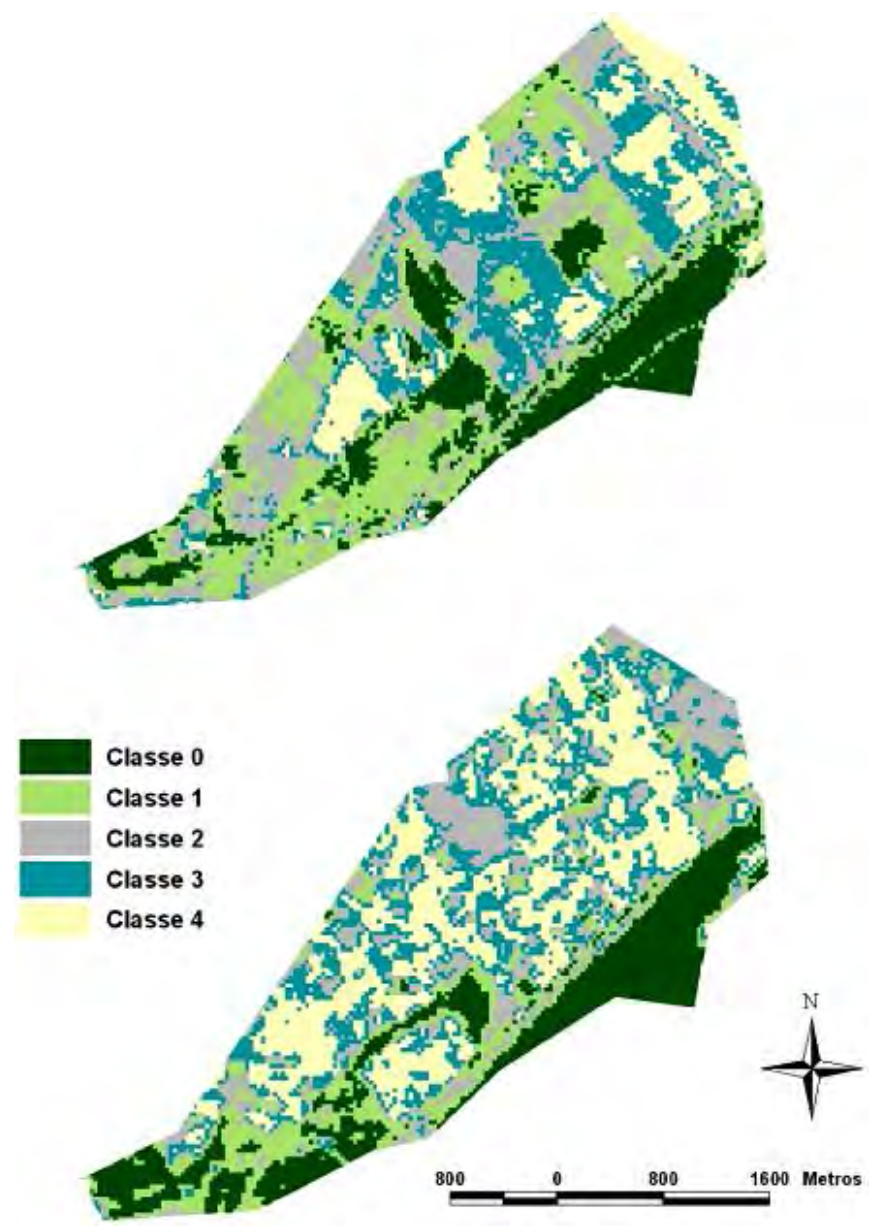

Figura 3. G rau de uso e ocupação do solo da bacia do córrego Ponte de Terra em 1986 (acima) 2003 (abaixo)

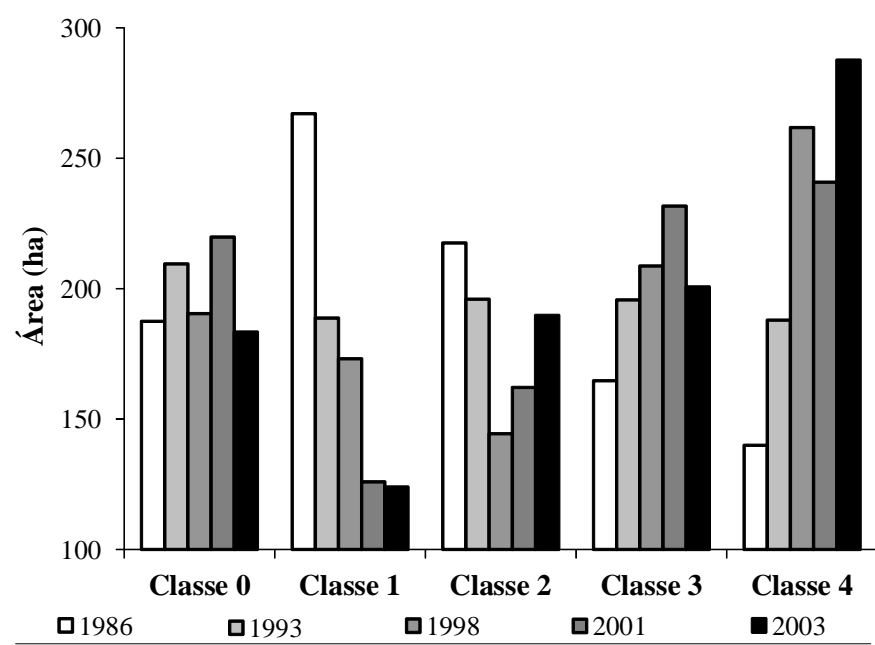

Figura 4. Evolução do uso e ocupação do solo na bacia, entre os anos de 1986 e 2003

período entre 1986 e 2003 e através dela se observa que, de fato, houve no período um aumento progressivo da proporção de classes 3 e 4 (alta modificação em relação à situação original), em detrimento das áreas de classe 1 e 2, sendo que a classe 0 (áreas não modificadas) foi pouco alterada no período.

A relativa estabilidade observada para a classe 0 (cerrado) pode ser explicada pelas áreas conservadas na parte sul da bacia (zona militar) e pela mata ciliar do córrego Ponte de Terra; já a redução das classes 1 e 2 (pequena e média modificação, respecivamente) e o aumento das classes 3 e 4 (maior intensidade de uso) se deveram ao processo de urbanização gradual da bacia, ao longo do período estudado.

A Figura 5 mostra a relação entre o Índice de Uso da Terra modificado $\left(\mathrm{LUI}_{\mathrm{m}}\right.$, dado pela Eq. 1) e o tempo, no período compreendido entre 1990 e 2003 . Esta figura indica que, no período estudado, houve um aumento significativo do grau de ocupação do solo, uma vez que o LUI ${ }_{m}$ passou de $2,8 \mathrm{em}$ 1990 para 3,3 em 2003 (aumento de 18\%).

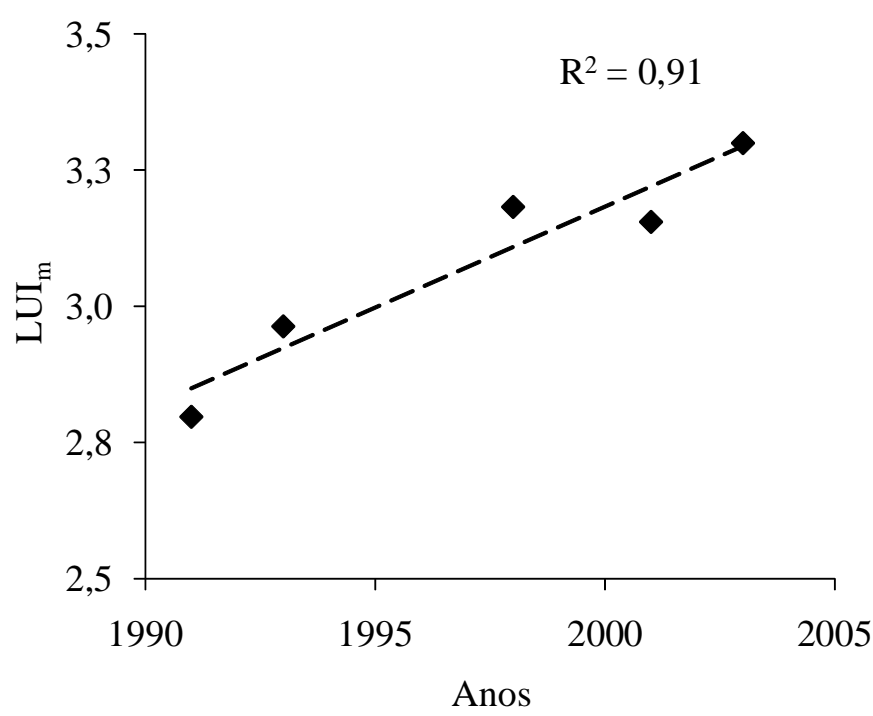

Figura 5. Variação do Índice de uso da terra modificado (LUI $\mathrm{m}_{\mathrm{m}}$ ) ao longo do tempo na bacia do Ponte de Terra

\section{Fragmentação da paisagem na bacia}

A evolução da fragmentação da paisagem na bacia entre os anos de 1986 e 2003, estimada pela entropia das classes de ocupação do solo (Eq. 2), pode ser observada na Figura 6. Além do uso mais intensivo do solo (indicado pelas Figuras 4 e 5), ocorreu, no período em tela, um aumento significativo na fragmentação da paisagem; em1986, a área de alta fragmentação da bacia, que era de 310 ha (32\% da área total) passou, em 2003, para 515 ha (53\%).

Constata-se claramente, na Figura 6, que em 1986 a bacia apresentava dominantemente um nível médio de fragmentação da paisagem (tons claros), ao contrário de 2003, quando predominou a alta fragmentação (tons escuros).

$\mathrm{O}$ aumento de fragmentação da paisagem da bacia no período estudado se deu pelo parcelamento do solo (condomínios), pela construção de casas e pelo aumento da densidade da rede viária (ruas). Como o pixel da imagem é de 30 x 30 $\mathrm{m}\left(900 \mathrm{~m}^{2}\right)$, ele foi capaz de captar essa mudança de padrão de ocupação. Pequenas diferenças entre as áreas de baixa fragmentação na Figura 6 talvez sejam devidas a diferenças radiométricas entre os sensores Landsat TM (1986) e ETM+ (2003), o que era esperado (Mather, 1999).

\section{Relação entre a intensidade de uso do solo e a fragmentação da paisagem}

A Figura 7, mostra a relação entre o grau de uso e ocupação do solo e a fragmentação da paisagem da bacia e por ela 


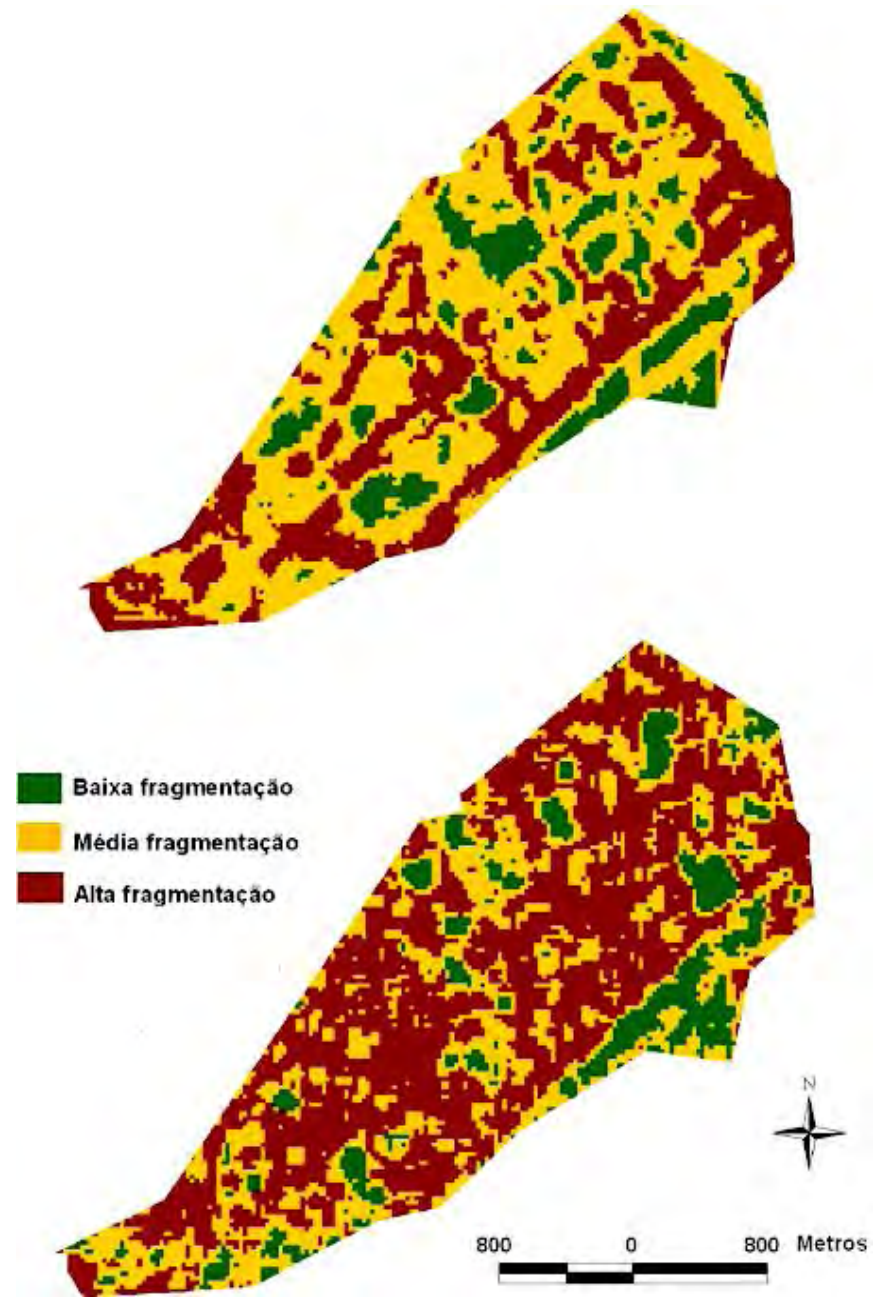

Figura 6. Grau de fragmentação da paisagem na bacia do Ponte de Terra em 1986 (acima) e 2003 (abaixo)

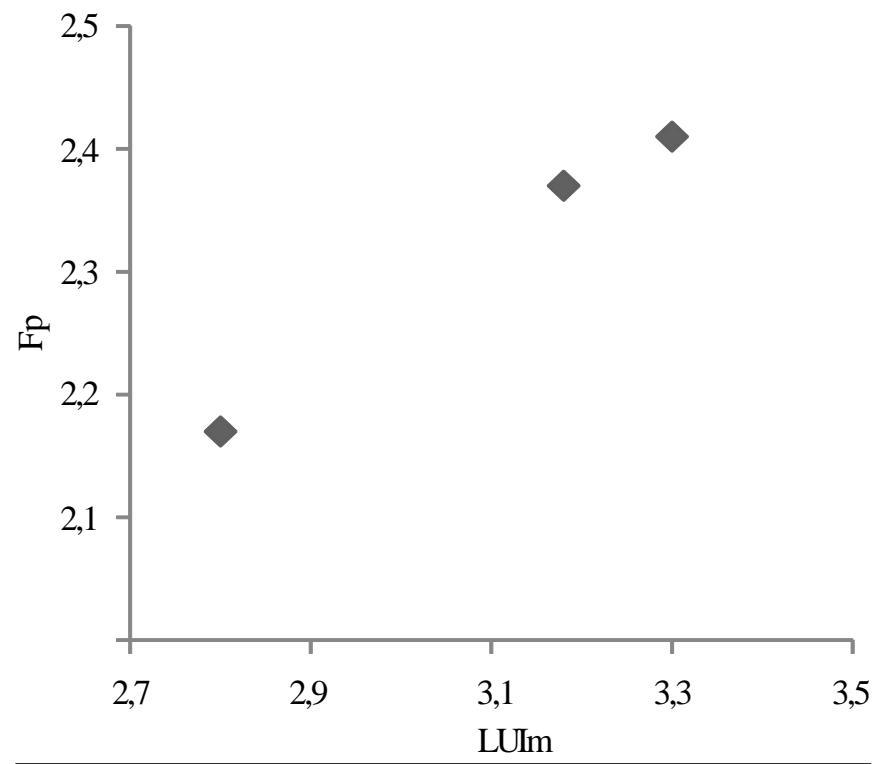

Figura 7. Relação entre o índice de ocupação do solo modificado (LUI $\mathrm{m}_{\mathrm{m}}$ e 0 índice de fragmentação da paisagem $\left(\mathrm{F}_{\mathrm{p}}\right)$ da bacia

se nota que a relação é direta, ou seja, com o aumento da intensidade de uso, dado pelo índice $\mathrm{LUI}_{\mathrm{m}}$ (Eq. 1) há um au- mento linear do grau de fragmentação da paisagem, dado pelo índice $\mathrm{F}_{\mathrm{p}}$ (Eq. 3).

Esta tendência também era esperada, uma vez que o padrão de redução da proporção de áreas de cobertura natural geralmente se dá de forma distribuída (fragmentada) na bacia, em um padrão de mosaico (Rutledge, 2003).

\section{Tendências nas séries temporais dos parâmetros de qualidade da água}

A Tabela 2, apresenta as médias, os coeficientes de variação e o índice de estacionariedade $t_{c}$ (Eq. 4) para os parâmetros de qualidade de água das 3 captações, no período entre 1992 e 2005, para as estações úmida e seca. Cada um dos valores anuais representa uma média de 4-6 amostras mensais, coletadas nos dois períodos do ano.

Constata-se, através da Tabela 2, que os valores médios dos parâmetros da estação úmida foram ligeiramente maiores que os da estação seca (excetuando-se o $\mathrm{NH}_{3}$ e o IQA); no

Tabela 2. Médias dos parâmetros de qualidade da água nas 3 captações (período úmido e seco)

\begin{tabular}{|c|c|c|c|c|c|c|}
\hline Ano & Cor (UH) & $\begin{array}{l}\text { Turbidez } \\
\text { (UT) }\end{array}$ & $\begin{array}{c}\text { Cond. } \\
\left(\mathrm{mS} \mathrm{cm}^{-1}\right)\end{array}$ & $\begin{array}{c}\text { DQO } \\
\left(\mathrm{mg} \mathrm{L}^{-1}\right)\end{array}$ & $\begin{array}{c}\mathrm{NH}_{3} \\
\left(\mathrm{mg} \mathrm{L}^{-1}\right)\end{array}$ & IQA \\
\hline \multicolumn{7}{|c|}{ Período Úmido } \\
\hline 1992 & 21,85 & 9,14 & 3,17 & 1,66 & 0,04 & 70,57 \\
\hline 1993 & 14,17 & 5,43 & 2,56 & 1,07 & 0,05 & 73,75 \\
\hline 1994 & 12,27 & 4,23 & 3,08 & 1,16 & 0,03 & 79,00 \\
\hline 1995 & 11,11 & 4,76 & 3,32 & 1,26 & 0,04 & 75,94 \\
\hline 1996 & 7,06 & 2,61 & 3,06 & 1,01 & 0,03 & 80,89 \\
\hline 1997 & 11,13 & 5,58 & 4,42 & 1,18 & 0,04 & 78,03 \\
\hline 1998 & 11,48 & 5,11 & 5,94 & 1,42 & 0,06 & 76,57 \\
\hline 1999 & 7,44 & 3,63 & 4,19 & 1,29 & 0,03 & 77,68 \\
\hline 2000 & 6,94 & 2,94 & 4,74 & 1,80 & 0,04 & 78,41 \\
\hline 2001 & 9,67 & 3,69 & 5,55 & 1,59 & 0,08 & 80,84 \\
\hline 2002 & 11,27 & 4,79 & 5,44 & 1,72 & 0,08 & 75,64 \\
\hline 2003 & 10,17 & 3,76 & 3,82 & 1,01 & 0,05 & 77,33 \\
\hline 2004 & 14,47 & 7,56 & 3,90 & 1,52 & 0,03 & 75,77 \\
\hline 2005 & 13,11 & 4,54 & 3,37 & 2,05 & 0,04 & 78,00 \\
\hline Média & 11,58 & 4,84 & 4,04 & 1,41 & 0,04 & 77,03 \\
\hline C.V. & 0,33 & 0,36 & 0,26 & 0,23 & 0,37 & 0,04 \\
\hline tc & 1,16 & 0,83 & 1,70 & $1,87^{*}$ & 0,81 & 1,30 \\
\hline \multicolumn{7}{|c|}{ Período Seco } \\
\hline 1992 & 12,36 & 4,14 & 2,56 & 1,08 & 0,03 & 76,72 \\
\hline 1993 & 9,84 & 3,28 & 3,02 & 1,08 & 0,04 & 77,85 \\
\hline 1994 & 6,96 & 2,43 & 2,74 & 0,56 & 0,03 & 81,75 \\
\hline 1995 & 3,67 & 2,63 & 2,84 & 1,06 & 0,05 & 81,91 \\
\hline 1996 & 7,61 & 2,96 & 3,32 & 0,87 & 0,03 & 80,58 \\
\hline 1997 & 7,78 & 3,08 & 5,17 & 0,92 & 0,03 & 78,88 \\
\hline 1998 & 9,89 & 3,91 & 4,20 & 0,97 & 0,08 & 79,18 \\
\hline 1999 & 9,17 & 3,88 & 6,24 & 1,41 & 0,02 & 80,18 \\
\hline 2000 & 7,44 & 2,56 & 4,36 & 1,16 & 0,03 & 77,14 \\
\hline 2001 & 8,17 & 2,62 & 5,96 & 1,31 & 0,07 & 80,29 \\
\hline 2002 & 11,78 & 5,01 & 5,35 & 1,30 & 0,06 & 74,80 \\
\hline 2003 & 9,00 & 3,13 & 4,23 & 1,03 & 0,12 & 79,07 \\
\hline 2004 & 8,22 & 2,84 & 3,46 & 1,15 & 0,05 & 78,90 \\
\hline 2005 & 8,11 & 3,12 & 3,11 & 4,29 & 0,03 & 76,93 \\
\hline Média & 8,57 & 3,26 & 4,04 & 1,30 & 0,05 & 78,87 \\
\hline C.V. & 0,25 & 0,22 & 0,31 & 0,68 & 0,57 & 0,03 \\
\hline tc & 0,05 & 0,07 & 1,58 & $2,21 *$ & 1,15 & 1,07 \\
\hline
\end{tabular}

$* \mathrm{t}_{\mathrm{c}}>\mathrm{t}$ (significativo) a nível de $95 \%$ 
caso do IQA, maiores valores significam água de melhor qualidade. Este comportamento é coerente, uma vez que durante a época chuvosa o transporte de nutrientes pela enxurrada é maior que na época seca.

Conforme indicam os valores de $\mathrm{t}_{\mathrm{c}}$ da Tabela 2 , apenas a DQO apresentou tendência significativa de aumento no período estudado, quando os valores médios das 3 captações foram considerados. Os outros parâmetros não apresentaram tendências de aumento, de diminuição ou de ressaltos (jumps) significativos no período, indicando que, apesar do aumento significativo da ocupação do solo, o sistema (bacia) apresentou uma alta resiliência durante o período estudado, mesmo com uma significativa alteração da cobertura e intensidade de ocupação do solo no período (Figuras 3 e 6).

De maneira geral, a qualidade da água do manancial durante o período estudado pode ser considerada boa, conforme indicam os valores de IQA (entre 70 e 80, para ambas as estações); não houve, tampouco, correlação significativa entre os 6 parâmetros de qualidade de água estudados.

Como a maioria dos trabalhos que detectaram correlações significativas entre o grau de ocupação do solo (pela urbanização, estradas etc) e a qualidade da água foi conduzida em regiões temperadas (Johnson et al., 1997; Hunsaker et al., 1998; Rhodes et al., 2001; Riemann et al., 2003), as quais podem apresentar resiliência distinta daquelas de regiões tropicais, fica difícil de fazer a comparação com os dados obtidos neste trabalho. Conforme indica a Figura 4, no final do período estudado (ano de 2005), mais de 60\% da área total da bacia apresentavam médio ou alto grau de ocupação do solo. Com o grau de alteração do uso do solo deste estudo, as bacias estudadas por Hunsaker et al. (1998) no leste dos EUA já teriam apresentado alteração nas variáveis de nitrogênio, fósforo e condutividade elétrica da água.

Ao contrário do observado, esperavam-se maiores valores de concentração para os parâmetros de qualidade de água na estação úmida, em função do maior escoamento superficial mas, mesmo nas amostras individuais, coletadas mensalmente, isto raramente ocorreu.

Uma provável explicação para este comportamento é o pequeno tempo de concentração da bacia (da ordem de minutos); como a frequência de coleta foi mensal, é improvável que um pico de hidrograma ou sedimentograma, responsável pelo transporte dos nutrientes, fosse capturado no processo de amostragem.

A Figura 8 apresenta a evolução da DQO (média das 3 captações) no período entre 1992 e 2005 , para as estações úmida e seca, nas quais se nota tendência significativa de aumento com o tempo $\left(\mathrm{t}_{\mathrm{c}}>1,8\right)$, principalmente nos 2 últimos anos da série.

Não está claro o motivo pelo qual a DQO apresentou tendência significativa de aumento no período estudado; talvez a maior persistência de eventuais materiais carbonáceos na água, mais persistentes (NSF, 1995), tenha permitido sua detecção, ao contrário dos outros compostos analisados, que apresentam menor persistência no ambiente (Novotny \& Chesters, 1981). Além disso, o arranjo espacial fragmentado da ocupação do solo da bacia, conforme indicam as Figuras 3 e 6, pode ter contribuído para a alta variância nos parâme-

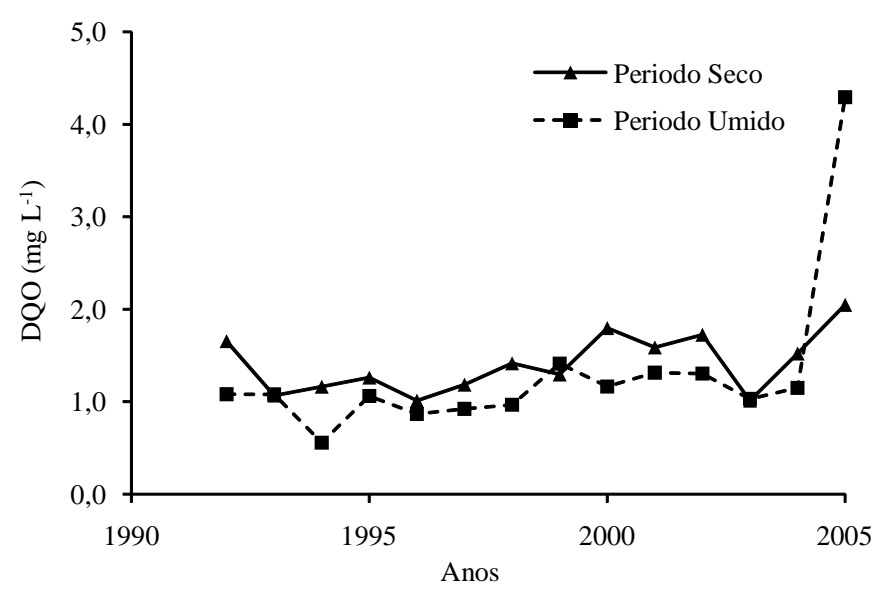

Figura 8. Evolução da demanda química de oxigênio (DQ 0) (média das 3 captações) no período entre 1992 e 2005 (períodos seco eúmido)

tros de qualidade de água (excetuado-se o IQA), mascarando eventuais tendências de aumento em seus valores. Gergel (2005), estudando o comportamento da variação da qualidade da água em várias bacias, concluiu que a variância máxima observada nos parâmetros físicos e químicos da água ocorreu quando a alteração atingia $65 \%$ da cobertura original. No caso da bacia do córrego Ponte de Terra, somando-se as áreas das classes 2, 3 e 4 (alterações média, alta, e muito alta, respectivamente), obtém-se um valor médio de 606 ha (62\% da área total da bacia), exatamente na faixa sugerida por Gergel (2005).

A Tabela 3 apresenta as médias dos parâmetros de qualidade da água de cada uma das 3 captações da bacia, no período entre 1992 e 2005, para as estações úmida e seca. Nesta tabela, se observa a ausência de variação significativa da qualidade da água nas 3 captações, no período estudado, em função do reduzido coeficiente de variação $(\mathrm{CV}<0,3)$, indicando que as qualidades de água são semelhantes.

Tabela 3. Médias dos parâmetros de qualidade da água nas 3 captações, no período entre 1992 e 2005 (período úmido e seco)

\begin{tabular}{|c|c|c|c|c|c|c|}
\hline Captação & Cor (UH) & $\begin{array}{l}\text { Turbidez } \\
\text { (UT) }\end{array}$ & $\begin{array}{c}\text { Cond. } \\
\left(\mathrm{mS} \mathrm{cm}^{-1}\right)\end{array}$ & $\begin{array}{c}\mathrm{DQO} \\
\left(\mathrm{mg} \mathrm{L}^{-1}\right)\end{array}$ & $\underset{\left(\mathrm{mg} \mathrm{L}^{-1}\right)}{\mathrm{NH}^{3}}$ & IQA \\
\hline \multicolumn{7}{|c|}{ Período Úmido } \\
\hline 1 & 8,16 & 3,22 & 4,74 & 1,52 & 0,05 & 76,80 \\
\hline 2 & 12,96 & 5,72 & 3,59 & 1,38 & 0,04 & 76,36 \\
\hline 3 & 13,62 & 5,59 & 3,79 & 1,34 & 0,04 & 77,92 \\
\hline Média & 11,58 & 4,84 & 4,04 & 1,41 & 0,04 & 77,03 \\
\hline C.V. & 0,26 & 0,29 & 0,15 & 0,07 & 0,05 & 0,01 \\
\hline \multicolumn{7}{|c|}{ Período Seco } \\
\hline 1 & 7,46 & 2,82 & 5,01 & 1,34 & 0,06 & 76,78 \\
\hline 2 & 9,19 & 3,60 & 3,50 & 1,29 & 0,04 & 79,73 \\
\hline 3 & 9,07 & 3,35 & 3,61 & 1,27 & 0,05 & 80,10 \\
\hline Média & 8,57 & 3,26 & 4,04 & 1,30 & 0,05 & 78,87 \\
\hline C.V. & 0,11 & 0,12 & 0,21 & 0,03 & 0,21 & 0,02 \\
\hline
\end{tabular}

Relação entre o grau de uso e ocupação do solo e a qualidade da água

A Figura 9 mostra a relação entre o grau de ocupação do solo, estimado pelo LUI ${ }_{m}$, e a DQO e IQA, para a estação seca, no período entre 1992 e 2003 (média das 3 captações). 
Observa-se, na Figura 9, que a correlação entre o $\mathrm{LUI}_{\mathrm{m}} \mathrm{e}$ os parâmetros DQO e IQA foi ligeiramente negativa $(r<0)$ e positiva $(r>0)$ respectivamente, porém sem apresentar tendência significância de aumento ou redução $\left(t_{c}<t\right)$.

No caso do IQA se nota, inclusive, ligeira melhora na qualidade da água com o aumento do grau de uso e ocupação do solo, estimado pelo LUI $_{\mathrm{m}}$. Como o IQA é o resultado da combinação de vários parâmetros físicos e químicos da água, o aumento de alguns deles pode ter sido compensado pela redução de outros, mantendo o índice praticamente inalterado durante o período estudado.

Considerando que o IQA é um índice integrado de qualidade da água, o fato dele não ter apresentado piora no período estudado nem ter sido correlacionado com o $\mathrm{LUI}_{\mathrm{m}}$ indica que a bacia (possivelmente sua zona ripária) pode ter absorvido a maior parte dos impactos resultantes do processo de uso e ocupação do solo ou, ainda, que o arranjo espacial fragmentado da cobertura do solo pode ter causado alta variância no processo de transporte de poluentes, mascarando eventuais tendências de piora.

Como se trata de região peri-urbana, na qual as áreas impermeabilizadas (edificações, ruas pavimentadas etc) ainda são relativamente baixas, é provável que o limite de $10 \%$ de impermeabilização, relacionado ao início da degradação dos mananciais, conforme indicado por Booth \& Jackson (1997),

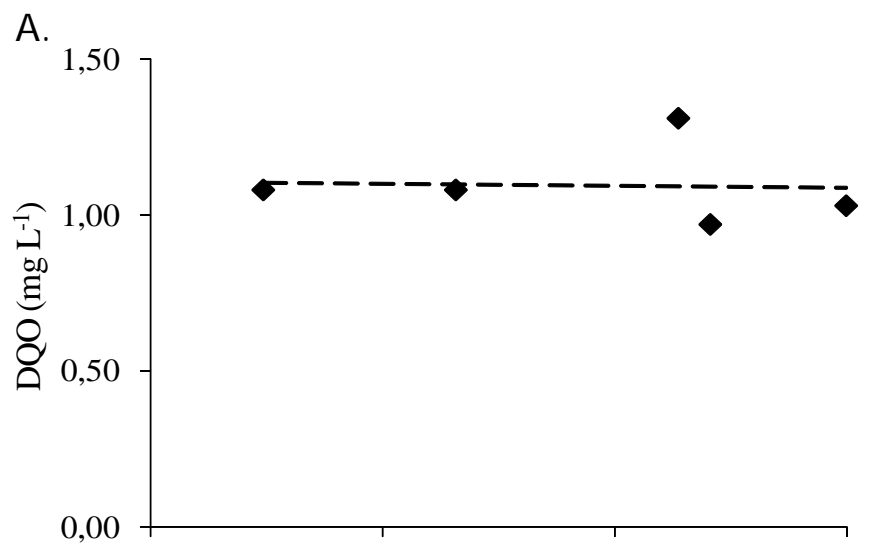

B.

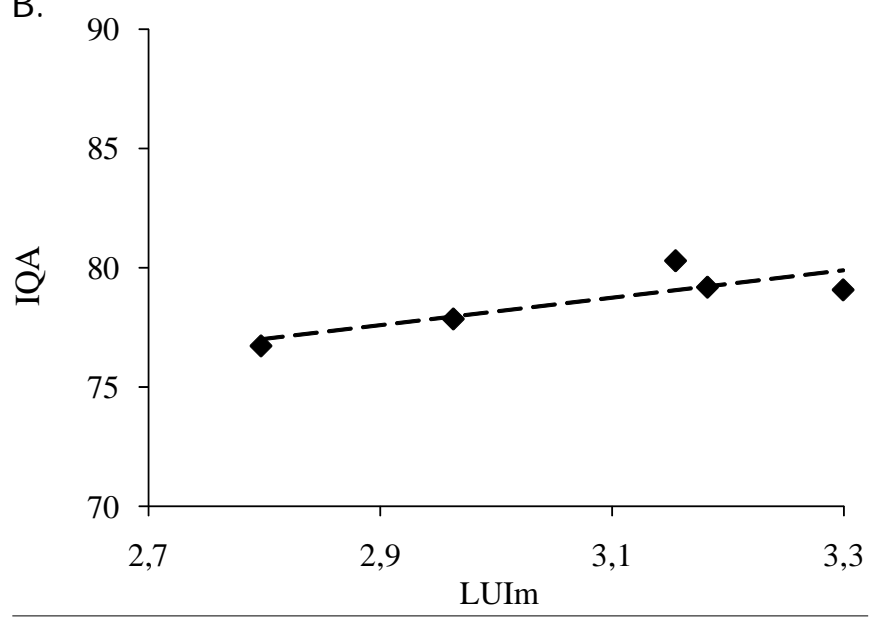

Figura 9. Relação entre a demanda química de oxigênio (DQ 0) (A), índice de qualidade de água (IQ A) (B) e o índice de ocupção do solo modificado (LUI $\left.\mathrm{m}_{\mathrm{m}}\right)$ para a estação seca (média das 3 captações) não tenha sido atingido. Uma outra possibilidade é o alto poder tampão da zona ciliar da bacia (relativamente preservada), ter reduzido eventuais impactos oriundos da urbanização das vertentes da bacia.

\section{CONCLUSÕES}

1. No período entre 1986 e 2003 ocorreu um aumento significativo do grau de ocupação do solo na bacia estudada, através do parcelamento do solo e da construção de casas e ruas.

2. A fragmentação da paisagem da bacia, medida por um índice no qual se usa a entropia das imagens de satélite $\left(\mathrm{F}_{\mathrm{p}}\right)$, também aumentou de forma significativa no período.

3. Os parâmetros de qualidade da água não apresentaram aumentos significativos no período estudado, excetuando-se a DQO, com tendência significativa de aumento, em ambas as estações (seca e úmida).

4. Apesar de os valores dos parâmetros de qualidade da água do período úmido terem sido, em média, um pouco maiores que os do período seco, a diferença não foi estatisticamente significativa.

5. Não houve correlação significativa entre o grau de uso e a ocupação da terra, estimado pelo $\mathrm{LUI}_{\mathrm{m}}$, e os parâmetros de qualidade da água, no período entre 1993 e 2003.

6. A baixa frequência de amostragem de qualidade da água durante o período, insuficiente para detectar eventuais picos de concentrações de poluentes, pode ter contribuído para a relativa estacionariedade dos parâmetros durante a estação úmida. Isso poderia ser evitado com uma maior freqüência de amostragem.

\section{AGRADECIMENTOS}

Os autores agradecem a atenção da CAESB no fornecimento dos dados de qualidade de água da Bacia do Ponte de Terra.

\section{LITERATURA CITADA}

Allan, J. D. Influence of land use and landscape setting on the ecological status of rivers. Limnetica, v.23 p.187198, 2004.

Booth, D. B.; Jakson, C. R. Urbanization of aquatic systems: Degradation thresholds, stormwater detection, and the limits of mitigation. Journal of the American Water Resources Association, v.33 n.5. p.1077-1090, 1997.

Cada, G. F.; Hunsaker, C. T. Cumulative impacts of hydropower development: Reaching a watershed impact assessment. The Environmental Professional, v.12, n.1, p.2-8, 1990.

Clinton, B. D.; Vose, J. M. Variation in stream water quality in na urban headwater stream in the southern Appalachians. Water, Air, and Soil Pollution, v.169, p.331-353, 2006.

Gergel, S. E. Spatial and non-spatial factors: When do they affect landscape indicators of watershed loading? Landscape Ecology v.20, p.177-189, 2005. 
Herlihy, A. T.; Stoddard, J. L.; Johnson, C. B. The relationship between stream chemistry and watershed land cover data in the Mid-Atlantic region, US. Water, Air, and Soil Pollution, v.105, p.377-386, 1998.

Houser, J., Mulholland, P., Maloney, K. O. Upland disturbance affects headwater stream nutrients and suspended sediments during baseflow and stormflow. Journal of Environmental Quality, v.35, p.352-365, 2006.

Hunsaker, C. T.; Jackson, B. L.; Simcock, A. Regional assessment for watershed management in the Mid-Atlantic states. In: Reimold, R.D. (ed.): Watershed management: Practice, policy and coordination. New York: McGraw-Hill, 1998. p.11-34.

Johnson, L. B.; Richards, C.; Host, G. E.; Arthur, J. W. Landscape influences on water chemistry in Midwestern stream ecosystems. Freshwater Biology, v.37, p.193-208, 1997.

Mather, P. M. Computer processing of remotely-sensed images: An introduction. New York: Wiley, 1999. 292p.

May, C. W.; Horner, R. R.; Karr, J.R.; Mar, B. W.; Welch, E. B. Effects of urbanization on small streams in the Puget Sound ecoregion. Watershed Protection Techniques, v. 2, n.4, p.483-494, 1999.

NSF - National Sanitation Foundation. Standard methods for the examination of water and wastewater. Washington: APHA, 1995. 9.060p.

Novotny, V.; Chesters, G. Handbook of nonpoint pollution. New York: van Nostrand, 1981. 555p.

Ometo, J. P.; Martinelli, L. A.; Ballerster, M. A.; Gessner, A.; Krusche, A. V.; Victoria, R. L.; Williams, M. Effects of land use on water chemistry and macroinvertebrates in two strea$\mathrm{ms}$ of the Piracicaba river basin, Brazil. Freshwater Biology, v.44, p.327-337, 2000.
Rhodes, A. L.; Newton, T. M.; Pufall, A. Influences of land use on water quality of a diverse New England watershed. Environmental Science and Technology, v.35. p. 3640-3645, 2001.

Ricotta, C.; Corona, P.; Marchetti, M.; Chirici, G. On parametric fragmentation measures. European Journal of Forest Research, v.125, n.4, p.441-444, 2006.

Riemann, R.; Riva-Murray, K.; Murdoch, P. Effects of forest fragmentation and urbanization on stream conditions-The development of relevant landscape parameters and source datasets for effective monitoring. Proc. of the 2003 Convention of the Society of American Foresters, 2004, Buffalo Anais...Bufalo: CSAF, 2004. p.234-235.

Roy, A. H.; Resemond, M. J.; Paul, M. J.; Leigh, D. S.; Wallace, J. B. Stream macroinvertebrate response to catchment urbanization (Geórgia, USA). Freshwater Biology, v.48, p.329-346, 2003.

Rutledge, D. Landscape indices as measures of the effects of fragmentation: Can pattern reflect process? Document Internal Series 98, Auckland: Department of Conservation, 2003, 27p.

Salas, J. D. Analysis and modeling of hydrologic time series, in Maidment, D. (ed): Handbook of hydrology. New York: McGraw-Hill, 1992.p.19.1-19.72.

Schueler, T. Planning for urban stream protection. Metropolitan Washington: Council of Governments, 1994. 30p.

Shannon, C. E. The mathematical theory of communication. Bell System Technology Journal, v.27, p.379-423, 623-656, 1948.

UNESCO - United Nations Education, Science and Cultural Organization. Vegetação no Distrito Federal: Tempo e espaço. Brasília: UNESCO, 2000.55p. 